\title{
有机小分子催化的烯酮的不对称环加成反应
}

\author{
王爱娥* 张金龙 \\ (厦门大学化学化工学院 厦门 361005)
}

\begin{abstract}
摘要 重点从立体选择性和催化机理方面，总结了不同的有机小分子催化剂在烯酮的[2+2]和[4+2]不对称环加成反 应中的应用.
\end{abstract}

关键词 烯酮; 有机小分子催化; 不对称环加成反应

\section{Organocatalytic Asymmetric Cycloaddition Reaction of Ketenes}

\author{
Wang, Aie* Zhang, Jinlong \\ (College of Chemistry and Chemical Engineering, Xiamen University, Xiamen 361005)
}

\begin{abstract}
In this review, organocatalytic asymmetric [2+2] and [4+2] cycloaddition reactions of ketenes are summarized with emphasis on the selectivities and mechanisms of different catalysts.

Keywords ketenes; organocatalysis; asymmetric cycloaddition reaction
\end{abstract}

近年来有机小分子催化成为不对称催化的研究热 点. 有机小分子催化剂通过分子中所含的 $N, O, P, S$ 等 富电子中心与反应物通过化学键、范德华作用力或者氢 键形成活性中间体，不仅能够加速反应的进程，而且可 以利用自身的结构因素来构建手性环境, 从而控制不对 称反应的立体选择性. 它具有催化活性高, 操作简单, 环境友好等优点, 在设计多组分合成或多步反应方面具 有巨大的应用价值. 此外, 具有亲核性的有机小分子催 化剂, 还能够实现分子内亲核/亲电中心的极性反转, 改 变常规反应模式, 为人们提供非传统方法构建 $\mathrm{C}-\mathrm{C}$ 键 的途径 ${ }^{[1]}$.

烯酮是一类重要的反应活性中间体, 它以其不同寻 常的物理性质和独特的化学反应性能引起众多化学家 的研究兴趣. 在不对称合成中, 通过使用手性催化剂, 可以实现对烯酩碳碳双键的不对称加成, 产生一个以上 的手性中心 ${ }^{[2,3]}$. 目前用于烯酮的不对称反应的催化剂 主要包括 Lewis 酸和有机小分子催化剂两大类. 前者主 要是金属 $\mathrm{Al}$ 或 $\mathrm{Ti}$ 与含 $\mathrm{N}, \mathrm{O}$ 原子的手性配体形成的络 合物, 后者包括金鸡纳生物碱、含二茂铁结构的手性
PPY (4-pyrrolidinopyridine) 以及 $\mathrm{N}$-杂化卡宾 $(\mathrm{NHC})$ 等 (Scheme 1). 这些有机小分子催化剂，正是经过一个亲 核催化的过程, 通过与烯酮形成两性离子烯醇盐, 使烯 酮 $\beta$-碳原子的极性发生反转, 由原来的亲电性变为亲核 性, 这样它就可以作为亲核试剂参与到一系列反应中, 如烯酮与亚胺、醛、酮的 $[2+2]$ 环加成, 烯酮与邻苯醌 衍生物的[4+2]环加成、烯酮的酯化、酰胺化和 $\alpha$-卤代 反应等. 其中, 烯酮的不对称环加成反应尤其受到人们 的特别关注,一些重要的合成中间体, 如 $\beta$-内酯、 $\beta$-内 酰胺、 $\delta$-内酯等可通过烯酮的[2+2]和[4+2]环加成方法 获得, 不但步骤简单, 而且符合绿色化学的要求. 本文 从立体选择性控制及反应机理方面, 对有机小分子催化 的烯酮的不对称环加成反应进行了综述.

\section{1 烯酮与亚胺、偶氮二碳酸酯以及亚硝基化合 物的不对称 $[2+2]$ 环加成反应}

$\beta$-内酰胺是一种非常重要的具有生物活性的化合 物, 作为一类广谱抗生素它已被成功应用于临床. 近年 的研究表明, $\beta$-内酰胺还是一种极具潜力的丝氨酸蛋白

\footnotetext{
*E-mail: aiewang@xmu.edu.cn

Received March 30, 2011; revised May 19, 2011; accepted June 16, 2100.

Project supported by the National Natural Science Foundation of China (No. 20902075), the Natural Science Foundation of Fujian Province (No. 2009J05037), the Research Fund for the Doctoral Program of Higher Education of China (No. 20090121120007), and the Scientific Research Foundation for the Returned Overseas Chinese Scholars, State Education Ministry.

国家自然科学基金(No. 20902075)、福建省自然科学基金(No. 2009J05037)、高等学校博士学科点专项科研基金(No. 20090121120007)、教育部留学回 国人员科研启动基金资助项目。
} 


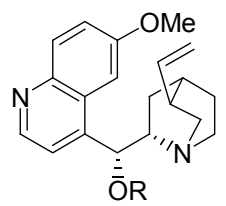

$Q(1 a): R=H$ $B Q(1 b): R=C O P h$ TMSQ (1c): $R=$ TMS $1 d \mathrm{R}=\mathrm{COEt}$

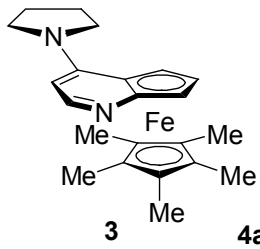

4a: $\mathrm{Ar}^{1}=\mathrm{Ph}, \mathrm{Ar}^{2}=\mathrm{Ph}, \mathrm{R}=\mathrm{TBS}$

4b: $\mathrm{Ar}^{1}=\mathrm{Ph}, \mathrm{Ar}^{2}=2-i-\mathrm{PrC}_{6} \mathrm{H}_{4}, \mathrm{R}=\mathrm{TBS}$

4c: $\mathrm{Ar}^{1}=3,5-\left(\mathrm{CF}_{3}\right)_{2} \mathrm{C}_{6} \mathrm{H}_{3}, \mathrm{Ar}^{2}=\mathrm{Ph}, \mathrm{R}=\mathrm{H}$

4d: $\mathrm{Ar}^{1}=\mathrm{Ph}, \mathrm{Ar}^{2}=2,4,6-\mathrm{Me}_{3} \mathrm{C}_{6} \mathrm{H}_{2}, \mathrm{R}=\mathrm{H}$

4e: $\mathrm{Ar}^{1}=3,5-\left(\mathrm{CF}_{3}\right)_{2} \mathrm{C}_{6} \mathrm{H}_{3}, \mathrm{Ar}^{2}=4-\mathrm{MeOC}_{6} \mathrm{H}_{4}, \mathrm{R}=\mathrm{H}$

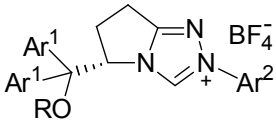

$\mathrm{NHC}$ precursor 5

5a: $A r^{1}=P h, A r^{2}=P h, R=T B S$

5b: $\mathrm{Ar}^{1}=\mathrm{Ph}, \mathrm{Ar}^{2}=2-i-\mathrm{PrC}_{6} \mathrm{H}_{4}, \mathrm{R}=\mathrm{TBS}$

5c: $\mathrm{Ar}^{1}=3,5-\left(\mathrm{CF}_{3}\right)_{2} \mathrm{C}_{6} \mathrm{H}_{3}, \mathrm{Ar}^{2}=\mathrm{Ph}, \mathrm{R}=\mathrm{H}$

5d: $\mathrm{Ar}^{1}=\mathrm{Ph}, \mathrm{Ar}^{2}=2,4,6-\mathrm{Me}_{3} \mathrm{C}_{6} \mathrm{H}_{2}, \mathrm{R}=\mathrm{H}$

5e: $\mathrm{Ar}^{1}=3,5-\left(\mathrm{CF}_{3}\right)_{2} \mathrm{C}_{6} \mathrm{H}_{3}, \mathrm{Ar}^{2}=4-\mathrm{MeOC}_{6} \mathrm{H}_{4}, \mathrm{R}=\mathrm{H}$

\section{Scheme 1}

酶抑制剂. 因此 $\beta$-内酰胺的合成, 特别是立体选择性合 成, 一直是有机合成化学和药物化学研究的热点. 而烯 酮与亚胺的 $[2+2]$ 环加成反应, 即 Staudinger 反应, 是合 成这类杂环化合物最经典也是最有效的方法.

\section{1 金鸡纳碱催化体系}

2000 年, Lectka 小组 ${ }^{[4]}$ 成功地将 $O$-苯甲酰奎宁 (BQ, 1b)作为亲核催化剂应用于烯酮和亚胺的不对称 $[2+2]$ 环加成反应中. 他们采用酰氯作为烯酮的前体, 在化学 计量质子海绵( $\mathrm{PS}$ )的存在下，与 $N$-Ts 亚胺基酯反应，以 $45 \% \sim 65 \%$ 的中等产率和 $95 \% \sim 99 \% e e$ 的高对映选择性 得到 $\beta$-内酰胺(Eq. 1).

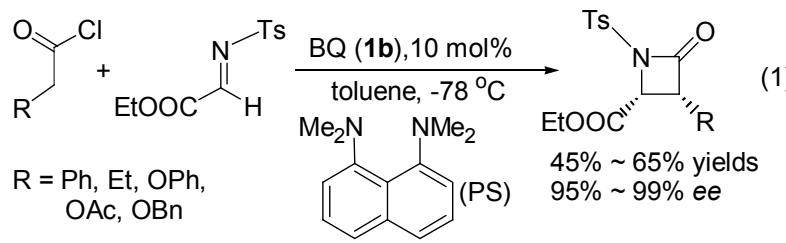

进一步的动力学研究 ${ }^{[5]}$ 表明, 以苯乙酰氯为前体时, 两性离子烯醇盐的生成并没有经历烯酮中间体, 而是直 接来自于酰氯(Scheme 2). 如途径 A 所示, BQ 和酰氯的 反应是整个反应的决速步, 生成的酰基胺盐在碱作用下
形成烯醇盐，烯醇盐很快与亚胺环合得到产物。而对于 含有吸电子基团的酰氯, 在质子海绵存在下，反应按途 径 B 进行，首先生成烯酮中间体.

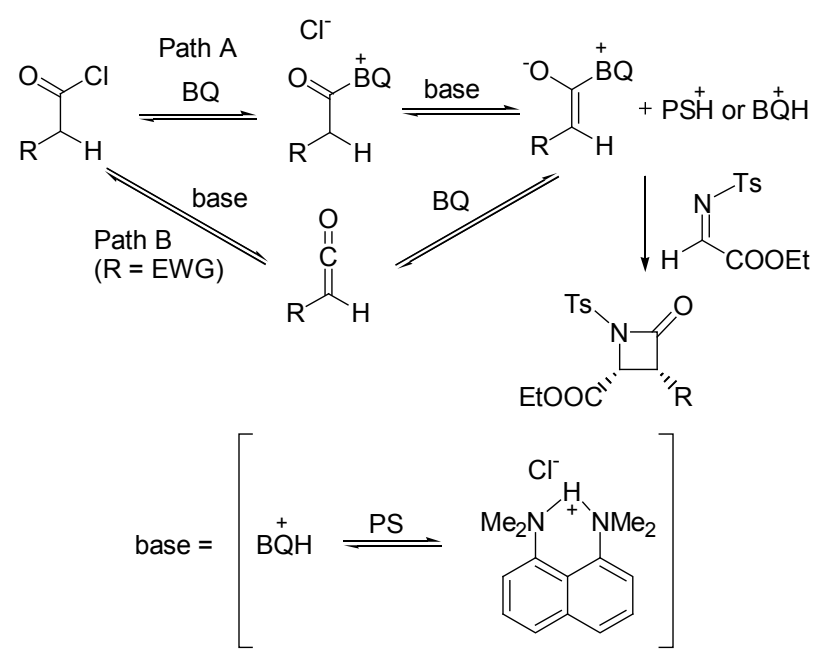

Scheme 2

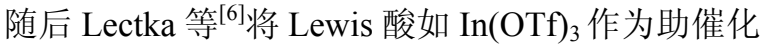
剂引入到金鸡纳碱催化的烯酮与亚胺的 $[2+2]$ 环加成反 应中, 产率由原来的 $45 \% \sim 65 \%$ 提高到 $92 \% \sim 98 \%$, 而 反应的对映选择性仍保持在 95\% 98\% ee (Scheme 3). Lewis 酸的引入增强了亚胺的亲电性 ${ }^{[7]}$, 使其更容易与 BQ 酰基化后形成的烯醇盐作用, 形成环化产物，从而 避免了其他副反应的发生.

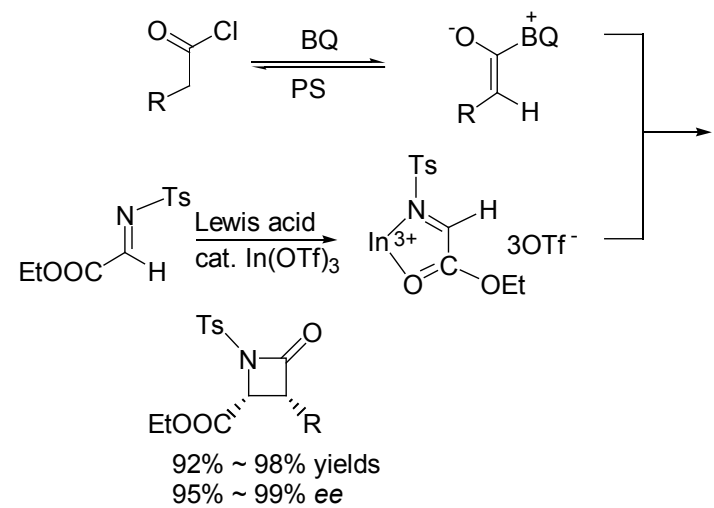

Scheme 3

\section{2 平面手性的 PPY (4-pyrrolidinopyridine)催化剂}

2002 年, $\mathrm{Fu}$ 等 ${ }^{[8]}$ 将具有平面手性的 PPY 催化剂 3 应 用到二取代烯酮和 $N$-Ts 亚胺的不对称 $[2+2]$ 环加成反 应中，以较高的收率和对映选择性得到含有 $\alpha$-季碳的 $\beta$ 内酰胺(Eq. 2). 对于非对称的烯酮, 主要得到 $c i s$ 构型的 产物 $(d r=8 \sim 15: 1)$. 而将相同的催化剂用于非对称烯 酮与 $N$-Tf 亚胺 ${ }^{[9]}$ 的环加成反应中，得到的 $\beta$-内酰胺是以 trans 构型为主的 $(d r=5 \sim 50: 1)$. 


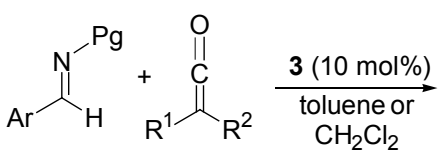

$$
\begin{aligned}
& \mathrm{Pg}=\mathrm{Ts} ; \mathrm{R}^{1}=\mathrm{R}^{2}=\left(\mathrm{CH}_{2}\right)_{5} \text {, Et } \\
& \mathrm{Pg}=\mathrm{Ts} ; \mathrm{R}^{1}=\mathrm{Et}, i-\mathrm{Bu} ; \mathrm{R}^{2}=\mathrm{Ph} \\
& \text { Ar } \\
& 76 \% \sim 93 \% \text { yields } \\
& 81 \% \sim 94 \% \text { ee } \\
& 88 \% \sim 98 \% \text { yields } \\
& 89 \% \sim 98 \% \text { ee } \\
& 8: 1 \sim 15: 1 d r \\
& \mathrm{Pg}=\mathrm{Tf} ; \mathrm{R}^{1}=\mathrm{Ph} ; \mathrm{R}^{2}=\mathrm{Me}, \mathrm{Et}, i-\mathrm{Bu} 60 \% \sim 89 \% \text { yields } \\
& 5: 1 \sim 50: 1 d r
\end{aligned}
$$

产物通过多步转化，可以用来制备手性 $\alpha$-羟基酸.

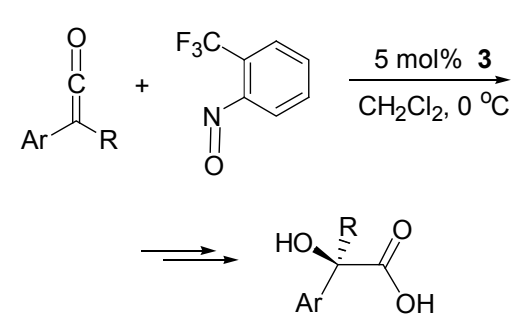<smiles>[Z10]C1([Y8])ON(c2ccccc2C(F)(F)F)C1=O</smiles>

$78 \% \sim 93 \%$ yields $78 \% \sim 98 \%$ ee

机理研究表明, 当使用 $N$-Ts 亚胺作底物时, 反应经 过一个常见的亲核催化的过程, 即亲核催化剂 PPY 首 先和烯酩作用形成两性离子烯醇盐 6, 6 对亚胺进行亲核 加成, 环化后得到 $\beta$-内酰胺; 而采用 $N$-Tf 亚胺时, 亲核 催化剂 PPY 首先进攻亚胺, 生成两性离子中间体 7, 7 作 为亲核试剂再与烯酮反应, 最后环化生成产物, 同时释 放出催化剂 PPY, 完成催化循环(Scheme 4).

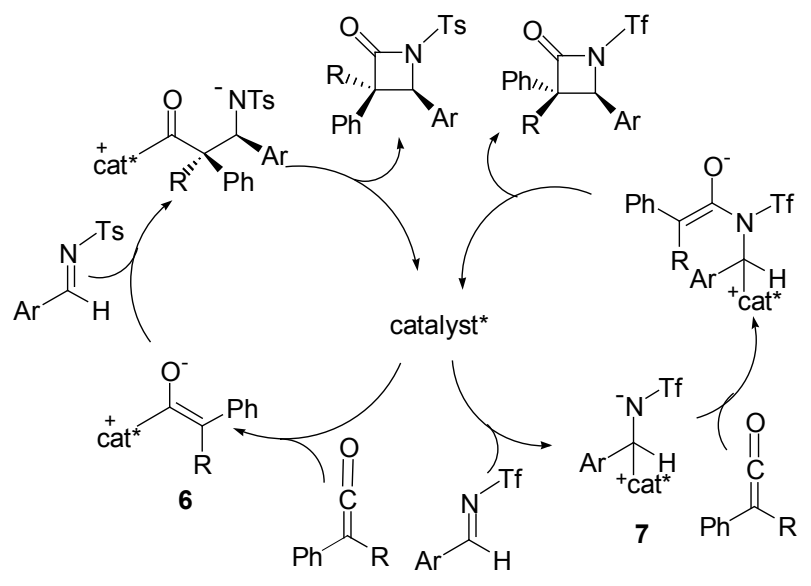

\section{Scheme 4}

上述平面手性的 PPY 催化剂也被 $\mathrm{Fu}$ 小组成功地应 用于二取代烯酮与偶氮二碳酸酯的 $[2+2]$ 环加成反应中 (Eq. 3), 用来合成手性氮杂 $\beta$-内酰胺 ${ }^{[10]} . \mathrm{Fu}$ 等认为该反 应的机理与烯酮和 $N$-Ts 亚胺的环加成反应的机理 (Scheme 4)类似, 也是催化剂首先与烯酮作用形成两性 离子烯醇盐 6 , 然后 6 与偶氮二碳酸酯发生反应得到环 化产物.

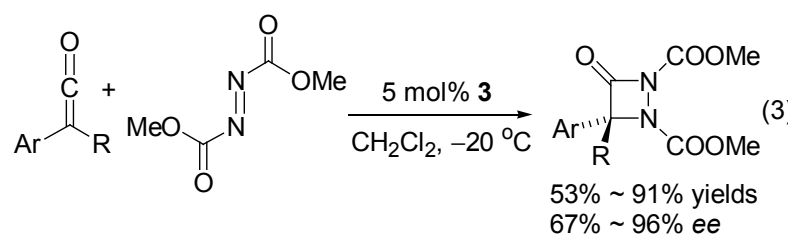

最近 $\mathrm{Fu}$ 小组又将他们发展的催化剂用于烯酮与亚

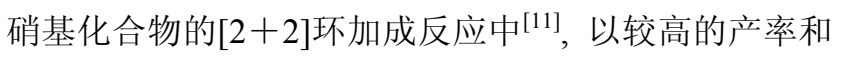
较好的对映选择性得到氧杂 $\beta$-内酰胺(Scheme 5). 所得

\section{Scheme 5}

\section{$1.3 \mathrm{~N}$-杂环卡宾(NHC)催化剂}

2008 年，叶松等 ${ }^{[12]}$ 发展了一类新型的手性三唑卡 宾前体 $5 \mathbf{a}$, 并成功地将其在 $\mathrm{Cs}_{2} \mathrm{CO}_{3}$ 作碱的条件下应用 于烷芳基烯酮与 $N$-Boc 亚胺的不对称 Staudinger 反应中, 获得高达 $99 \% e e$ 的对映选择性(Eq. 4). 叶松等认为 N杂环卡宾催化的烯酮与亚胺的 $[2+2]$ 环加成反应的机理 与 $\mathrm{Fu}$ 提出的平面手性的 PPY 3 催化的 Staudinger 反应 (Scheme 4) 类似, 当活性较低的 $N-\mathrm{Cbz}$ 和 $N$-Boc 亚胺与 烯酩的反应时, NHC 催化剂首先进攻烯酮, 而对于更缺 电子的 $N$-Ts 亚胺的 Staudinger 反应, 首先是亚胺与 $\mathrm{NHC}$ 加成.

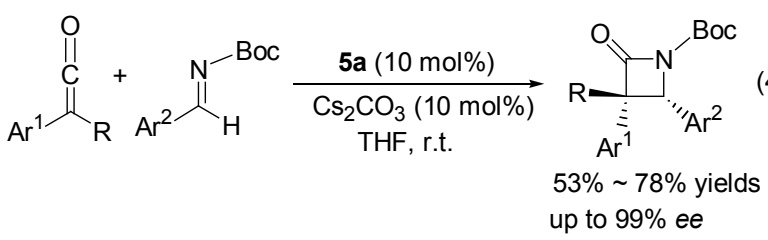

几乎同时, Smith 等 ${ }^{[13]}$ 使用 KHMDS 作碱, 将手性的 咪唑和三唑四氟硼酸盐以现场生成卡宾的方法, 用于二 苯基烯酮与 $N-T \mathrm{~s}$ 芳醛亚胺的 $[2+2]$ 环加成反应中，以较 高的产率和中等程度的对映选择性 $(<75 \% e e)$ 得到了手 性 $\beta$-内酰胺(Eq. 5).

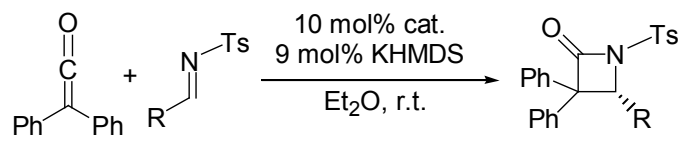

$\mathrm{R}=$ aryl, 2 -furyl

$79 \% \sim 96 \%$ yields

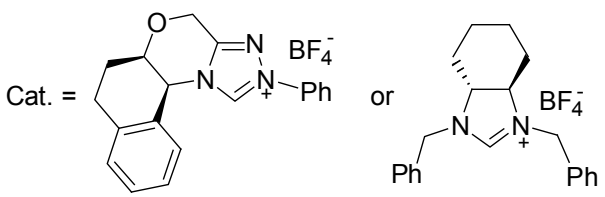

2009 年, 叶松等 ${ }^{[14]}$ 又将催化剂 $5 \mathbf{a}$ 应用于烯酮与偶 氮二碳酸酯的不对称 $[2+2]$ 环加成中, 以较高的产率和 高达 $91 \% e e$ 的对映选择性得到氮杂 $\beta$-内酰胺(Eq. 6). 与 苯甲酰基偶氮化合物和烯酮反应的反应 ${ }^{[15]}$ 不同，偶氮 二碳酸酯与烯酮反应只得到 $[2+2]$ 环加成的产物, 而没 
有[4+2]环加成产物的生成. 可见, 偶氮化合物 $\mathrm{N}$ 上的 取代基对反应的模式起着决定作用.

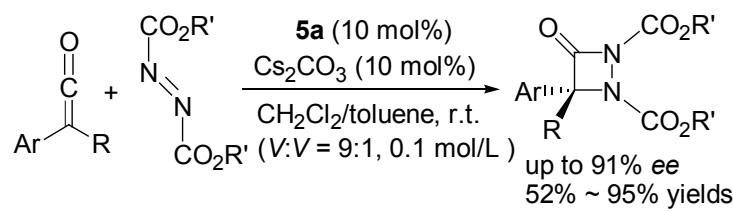

\section{4 其他催化剂}

2009 年, Wilhelm 小组 ${ }^{[16]}$ 报道了一种新型的手性咪 唑二硫代羧酸内盐催化的 Staudinger 反应(Eq. 7). 采用 8 作为催化剂, 各种 $N-p-\mathrm{Ns}$ 芳醛亚胺能与烯酮作用, 以 $96 \%$ 以上的产率和较高的立体选择性 (3 9 $: 1 d r$, $83 \% \sim 96 \% e e)$ 生成 $c i s$ 构型为主的 $\beta$-内酰胺.

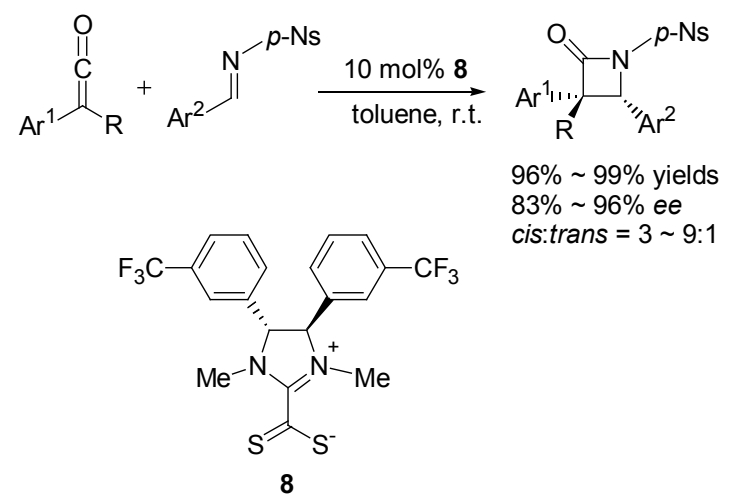

咪唑二硫代羧酸内盐可通过咪唑盐在碱性条件下 脱质子, 现场生成的 $\mathrm{N}$-杂环卡宾与 $\mathrm{CS}_{2}$ 加成来制备. 通 过一系列实验, Wilhelm 排除了从咪唑二硫代羧酸内盐 生成 $\mathrm{N}$-杂环卡宾催化的机理, 他们认为该反应中的亲 核催化剂是咪唑二硫代羧酸内盐, 它或者先活化烯酮, 生成两性离子烯醇盐, 再与亚胺环化, 或者先与非常缺 电子的 $N-p-\mathrm{Ns}$ 亚胺作用, 再与烯酮反应(Scheme 6).

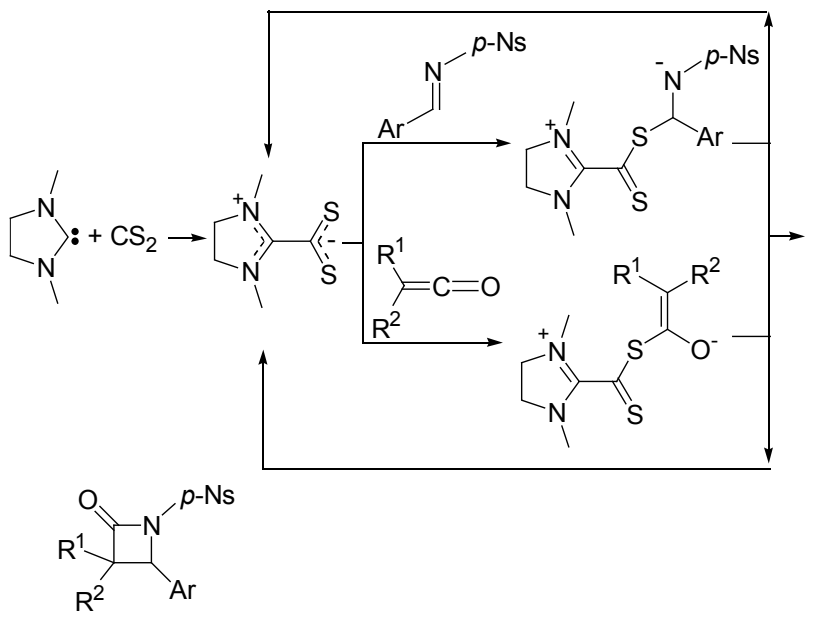

Scheme 6

\section{2 烯酮与醛酮的不对称[2+2]环加成和烯酮的}

\section{二聚反应}

烯酮与醛酮的 $[2+2]$ 环加成和烯酮的二聚反应，可 以用来合成 $\beta$-内酯. $\beta$-内酯一方面可以作为活性结构单 元，广泛应用于具有生物活性的天然产物的合成中，另 一方面还可以作为 “保护” 的羟醛缩合产物，应用于 polyketide 等天然产物的合成中.

\section{1 金鸡纳碱催化剂体系}

\section{1 .1 烯酮与醛酮的不对称 $[2+2]$ 环加成}

1982 年, Wynberg 和 Staring ${ }^{[17]}$ 首次将金鸡纳碱作为 亲核催化剂应用乙烯酮和三氯乙醛的不对称 $[2+2]$ 环加 成反应中，得到了 $95 \%$ 的产率和 $95 \%$ ee 的对映选择性 (Scheme 7). 所得 $\beta$-内酯水解之后可以转化为苹果酸, 通过使用奎宁丁 $(Q D, 2 \mathbf{a})$ 和奎宁 $(\mathrm{Q}, \mathbf{1 a})$ 作为催化剂, 可 以分别得到天然的 $(S)$-苹果酸和非天然的 $(R)$-苹果酸.

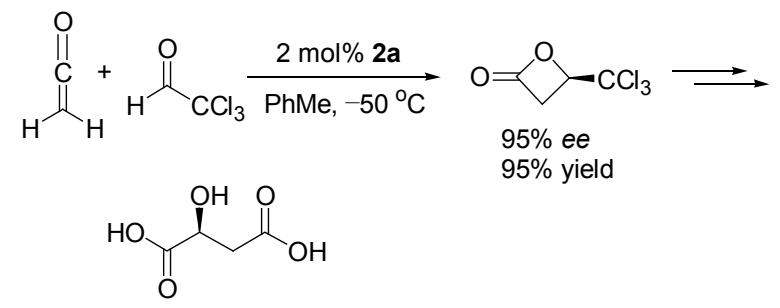

\section{Scheme 7}

随后，他们又将上述催化剂应用到乙烯酮和其他的

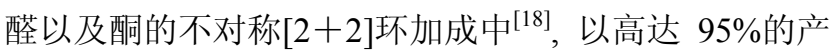
率和 $98 \% e e$ 的对映选择性得到含有手性季碳中心的 $\beta$ 内酯(Eq. 8).

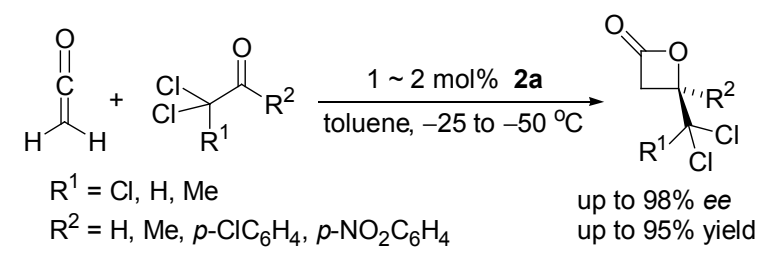

后来 Romo 小组 ${ }^{[19]}$ 对 Wynberg 的方法进行了改进, 他们采用乙酰氯为前体, 在 $\operatorname{EtN}(\operatorname{Pr}-i)_{2}$ 存在下现场生成 烯酩，这样就避免了过量气体乙烯酩的使用，使得实验 操作大为简化. Romo 等认为金鸡纳碱催化的烯酮与醛 (酮)的 $[2+2]$ 环加反应是一个亲核催化的机理，金鸡纳 碱首先与烯酮反应生成两性离子烯醇盐, 烯醇盐再与醛 (酤)加成、环合(Scheme 8).

2004 年, Nelson 小组 ${ }^{[20]}$ 报道了 $O$-TMS 奎宁(TMSQ, 1c)和 Lewis 酸 $\mathrm{LiClO}_{4}$ 共同催化的烯酮和醛的不对称 $[2+2]$ 环加成反应, 将底物的范围由原来的未取代的乙 烯酮和 $\alpha$-氯代乙醛扩展到甲基乙烯酮和普通的脂肪 


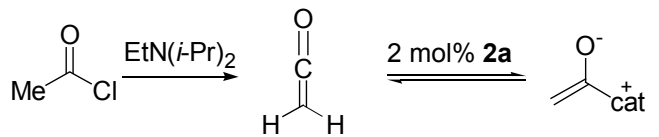

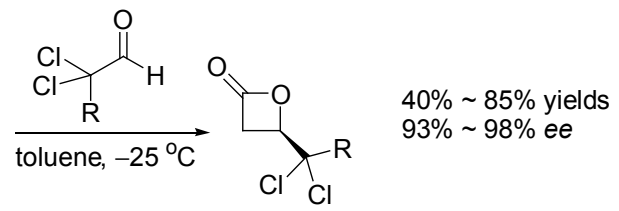

$\mathrm{R}=\mathrm{Bn}, \mathrm{C}_{6} \mathrm{H}_{13}, \mathrm{Piv}-\mathrm{O}\left(\mathrm{CH}_{2}\right)_{2}, i-\mathrm{Pr}$

\section{Scheme 8}

醛与芳香醛, 以较高的产率和很高的立体选择性得到顺 式 $\beta$-内酯(Eq. 9).

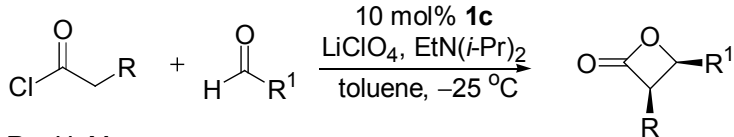

$$
\begin{aligned}
& \mathrm{R}=\mathrm{H}, \mathrm{Me} \text {; } \\
& \mathrm{R}^{1}=\mathrm{Cy}, \mathrm{BnOCH}_{2}, \mathrm{Ph}\left(\mathrm{CH}_{2}\right)_{2}, p-\mathrm{FC}_{6} \mathrm{H}_{4}, \quad 70 \% \sim 85 \% \text { yields } \\
& \text { o- } \mathrm{ClC}_{6} \mathrm{H}_{4}, \mathrm{o}-\mathrm{Tol} \\
& 84 \% \text { > } 99 \% \text { ee } \\
& >96 \% d r
\end{aligned}
$$

Nelson 等认为该反应的机理是: 现场生成的烯酮在 亲核催化剂和 Lewis 酸作用下首先生成金属配位的烯醇 盐, 烯醇盐再通过一个含有金属离子的六元环状过渡态 与醛进行加成, 最后环化生成 $\beta$-内酯(Scheme 9). 六元 环状过渡态的形成, 不仅活化了底物, 而且创造了一个 紧密的手性控制环境, 使得 $\mathrm{C}-\mathrm{C}$ 键的生成具有很高的 立体选择性.

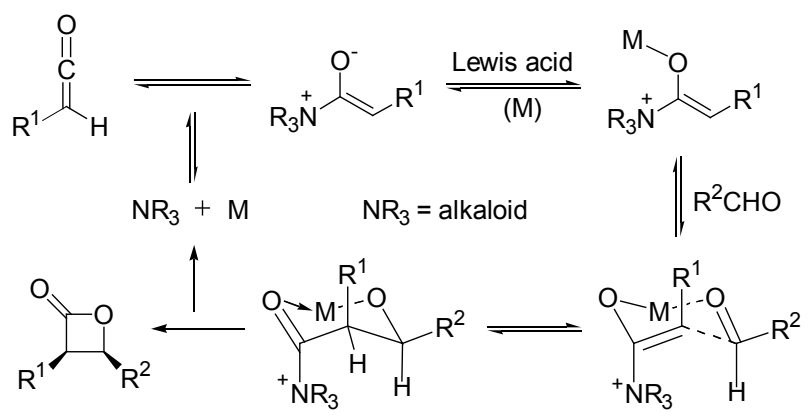

Scheme 9

2005 年 Calter 小组 ${ }^{[21]}$ 报道了镧系金属的三氟甲磺 酸盐作为助催化剂与 $O$-TMS 奎宁丁(TMSQD, 2c) 结合, 在 $\mathrm{EtN}(\mathrm{Pr}-i)_{2}$ 存在下酰氯和芳醛的 $[2+2]$ 环加成反应( $(\mathrm{Eq}$. 10). 产物的构型取决于酰氯上的取代基, 对于脂肪酰 氯得到的是反式构型为主的 $\beta$-内酯, 而烷氧酰氯主要得 到顺式构型的产物.

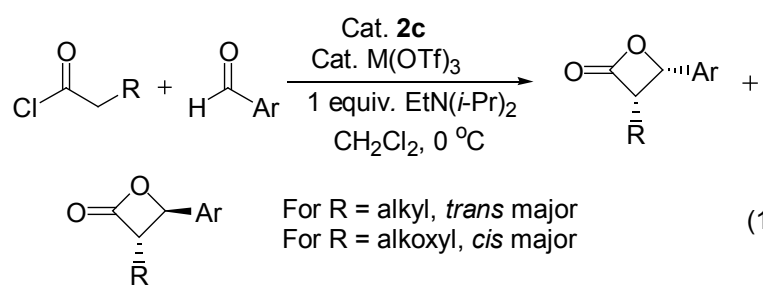

Calter 等认为，在 Lewis 酸作用下烯酮与 TMSQD 作用生成的金属烯醇盐，和 Lewis 酸活化的芳醛反应， 有两种可能的过渡态: 一种是只含有一个金属离子的紧 密的邻交叉式，另一种是含有两个金属离子的稳定的对 交叉式. 对于脂肪烯酮，更倾向于采用稳定的对位交叉 式, 因此主要得到反式构型的产物(Path A, Scheme 10). 而对于烷氧基取代的烯酮，在 Lewis 酸作用下与 TMSQD 作用形成鳌合型的金属烯醇盐，由于 $\mathrm{R}$ 基团和 金属配体之间的相互作用使得对交叉式不稳定，因此反 应更倾向于采用邻交叉式过渡态，得到顺式构型为主的 产物(Path B, Scheme 10)

Path A: alkyl-substituted acid chlorides open transition-state

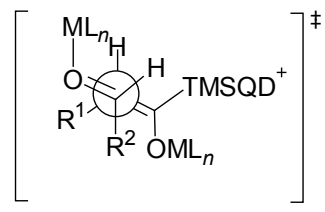
forms trans-lactone

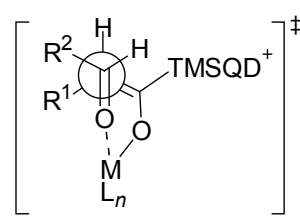

closed transition-state forms cis-lactone
Path B: alkoxy-substituted acid chlorides

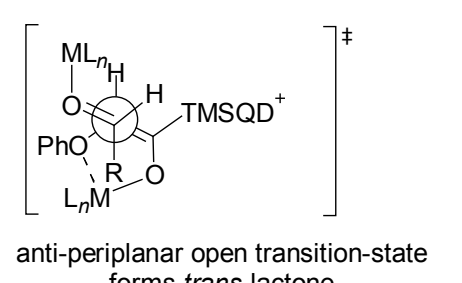
forms trans-lactone

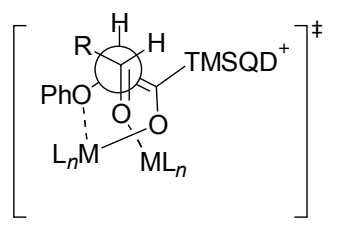

gauche open transiton-state forms cis-lactone

\section{Scheme 10}

2007 年 Lin 小组 ${ }^{[22]}$ 将亲核性的金鸡纳生物碱与 Lewis 酸结合起来, 发展了一类含有奎宁结构的 Salen 钴 的双官能团催化剂 9 (Eq. 11), 在乙烯酮与芐氧基乙醛 的[2+2]环加成反应中获得 $91 \%$ 的产率和大于 $99 \% \mathrm{ee}$ 的对映选择性.

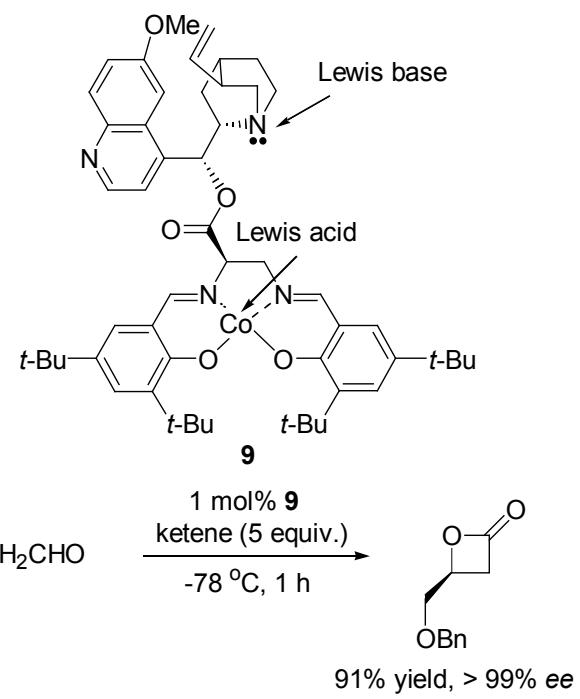




\section{1 .2 烯酮的二聚反应}

Calter 小组 ${ }^{[23]}$ 最早研究了金鸡纳碱催化的甲基烯酠 的不对称二聚反应, 发现奎宁丁 $(\mathrm{QD}, 2 \mathbf{2})$ 和 $O$-TMS 奎宁 丁 (TMSQD, 2c)最为优秀 $(98 \% e e)$ (Scheme 11), 而奎宁 $(\mathrm{Q}, 1 \mathrm{a})$ 只给出中等程度的结果 $(70 \% e e)$, 但是其 $O-\mathrm{TMS}$ 衍生物(TMSQ, 1c)仍表现出较高的对映选择性(90\% ee). Calter 等认为, 奎宁 $(\mathrm{Q}, \mathbf{1 a})$ 是由于与烯酮发生了部分酯 化形成 $O$-丙酰奎宁 $(1 \mathrm{~d}, 57 \% \mathrm{ee})$, 从而表现出较低的选 择性.

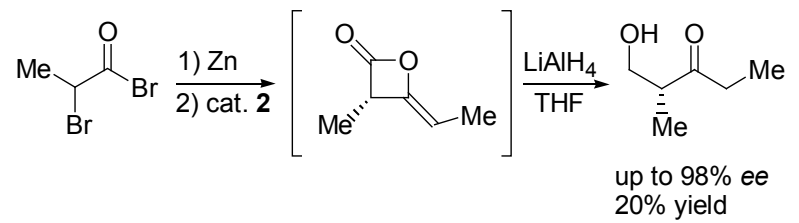

\section{Scheme 11}

后来 Calter 等 ${ }^{[24]}$ 改进了制备烯酮的方法, 采用一瓶 多步法实现了烯酮二聚、内酯开环、aldol 缩合一系列转 化(Scheme 12), 为多聚丙酸酯类衍生物的不对称合成 提供了一条方便有效的途径.

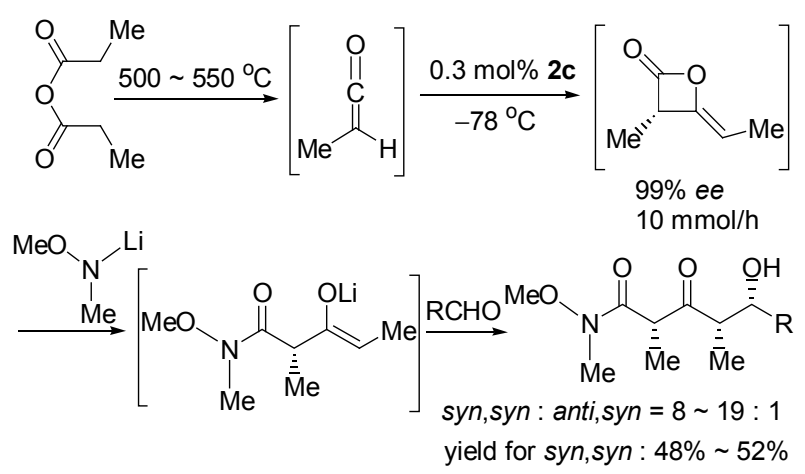

Scheme 12

2003 年 Calter 小组 ${ }^{[25]}$ 使用酰氯作为烯酮的前体, 在 化学计量 $\operatorname{EtN}(\operatorname{Pr}-i)_{2}$ 和催化量 $O$-TMS 奎宁(TMSQ, 1c) 存在下, 以很高的产率和对映选择性得到各种脂肪烯䣶 的二聚产物(Scheme 13).

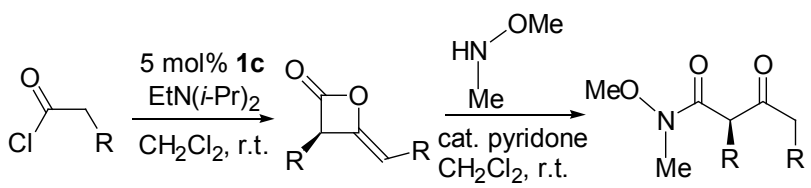

$\mathrm{R}=\mathrm{Me}, \mathrm{Et}, i-\mathrm{Pr}, t-\mathrm{Bu}, \mathrm{TIPSOCH}, \mathrm{MeO}_{2} \mathrm{CCH}_{2}$

$58 \% \sim 88 \%$ yields $91 \% \sim 96 \%$ ee

\section{Scheme 13}

机理研究表明, 酰氯脱去 $\mathrm{HCl}$ 形成烯酮是二聚反应 的决速步骤. 而亲核催化剂与烯酮加成生成的烯醇盐, 与另一分子的烯酮 (path A) 或者酰氯(path B) (Scheme
14)反应则决定着二聚反应的立体化学. 无论是采用制 备好的烯酮还是酰氯作为前体，二聚反应都可以按路径 $\mathrm{A}$ 的方式进行, 而路径 B 只有在使用酰氯为前体时才有 可能. Cater 等将各种催化剂分别应用到制备好的烯酮和 现场生成的烯酮中，发现每个催化剂在两种条件下都给 出相同的立体选择性，因此 Cater 等认为，无论采用制 备好的烯酮还是酰氯作为前体，烯酮二聚都按路径 $\mathrm{A}$ 的 方式进行.

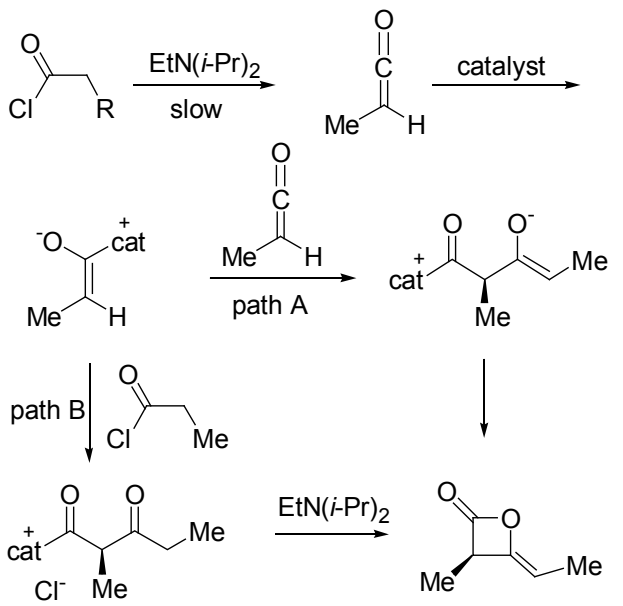

Scheme 14

\section{$2.2 \mathrm{~N}$-杂环卡宾(NHC)催化剂}

2008 年叶松报道了 $\mathrm{N}$-杂环卡宾催化的 2-酰基醛与 烯酮的不对称环加成反应 ${ }^{[26]}$. 使用他们课题组发展的 三唑卡宾 4a 作为催化剂, 各种烷芳基烯酮和二芳基烯 酮都能与 2-酰基醛发生反应，以较高的非对映选择性和 高达 $99 \% e e$ 的对映选择性得到含有相邻季碳中心和叔 碳中心的 $\beta$-内酯(Eq. 12). 对于活性比 2-酰基醛低的普 通芳醛，如 4-氯苯甲醛，在相同条件下与烯酮是不反应 的.

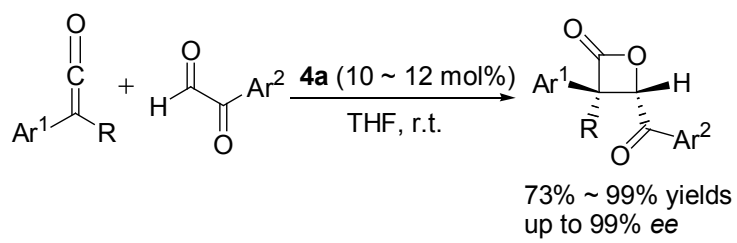

随后叶松等 ${ }^{[27]}$ 又将该类催化剂应用到烷芳基烯酮 与三氟苯乙酮的不对称加成反应中，以高达 $96 \% d r$ 的 非对映选择性和 $99 \%$ ee 的对映选择性得到了含有两个 相邻季碳中心的 $\beta$-内酯(Eq. 13).

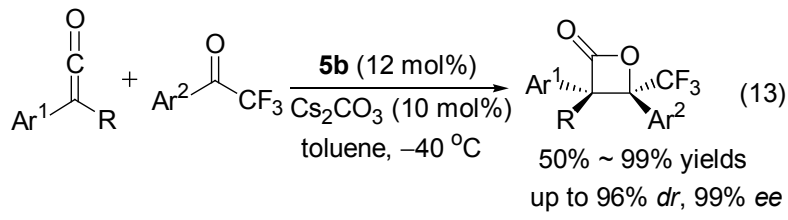

最近, 叶松课题组 ${ }^{[28]}$ 又成功地将他们合成的三唑 
卡宾催化剂应用于二取代烯酮与吲哚满二酮的环加成 反应中, 高立体选择性地合成出螺环吲哚酮- $\beta$-内酯化 合物(Eq. 14).

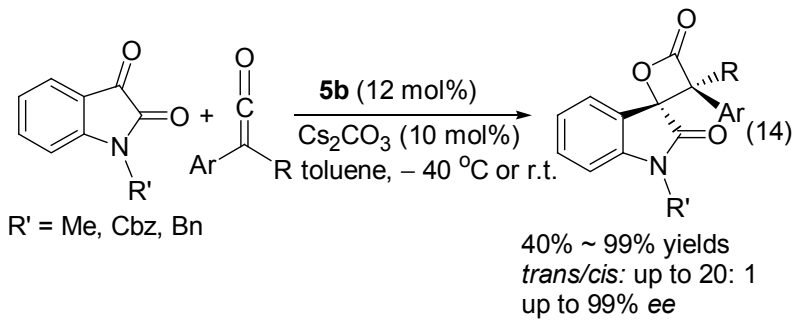

叶松也将他们课题组发展的三唑卡宾 $\mathbf{4}$ 作为亲核催 化剂成功应用于烷芳基烯酮的不对称二聚反应中 ${ }^{[29]}$, 以高达 $97 \% e e$ 的对映选择性得到含有 $\alpha$-手性季碳的 $\beta$ 内酯(Eq. 15). 和烯酮与亚胺和醛酮的反应不同的是, 这 里邻位含有裸露羟基的三唑卡宾比相应的羟基被 TMS 和 TBS 保护的催化剂表现出更好的诱导效果. 其中催 化剂 $4 \mathrm{e}\left[\mathrm{Ar}^{1}=3,5-\left(\mathrm{CF}_{3}\right)_{2} \mathrm{C}_{6} \mathrm{H}_{3}, \mathrm{Ar}^{2}=4-\mathrm{MeOC}_{6} \mathrm{H}_{4}\right]$ 的活性 和选择性最高. 一方面, $\mathrm{Ar}^{1}$ 上 $\mathrm{CF}_{3}$ 的引入增强了羟基形 成氢键的能力, 使催化剂的手性诱导能力提高, 另一方 面, 在 $\mathrm{Ar}^{2}$ 中引入给电子的 $\mathrm{OCH}_{3}$ 从一定程度上增强了 $\mathrm{N}$-杂化卡宾的亲核性, 从而表现出较高的催化活性.

$$
\underset{\mathrm{R}}{\mathrm{THF}, \text { r.t. }}
$$

叶松等认为 NHC 催化的烯酮二聚的机理为 (Scheme 15): NHC 首先作为亲核试剂进攻烯酮生成烯 醇三唑盐 9, 烯醇盐 9 对另一分子的烯酮加成形成中间 体 10, 中间体 10 可以作为 $\mathrm{O}$-亲核试剂发生分子内亲核 取代反应生成 $\beta$-内酯 11 (path a), 也可以作为 $\mathrm{C}$-亲核试 剂生成 $\beta$-二酮 12 (path b). 可能由于 $\mathrm{C}$-亲核试剂和三唑 卡宾之间有较大的空间排斥作用, 反应中没有检测到二 酮 12 的生成.

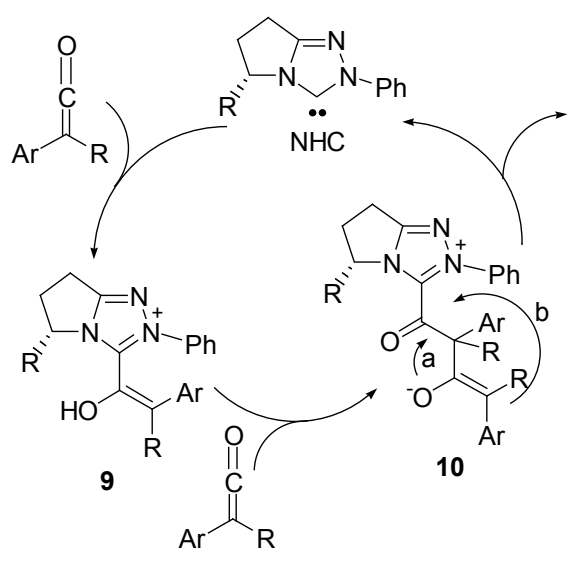

Scheme 15

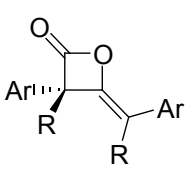

11 (path a)

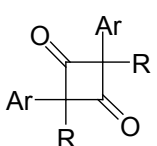

12 (path b) (not observed) 


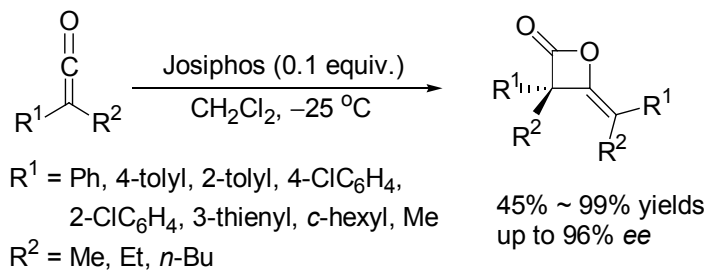

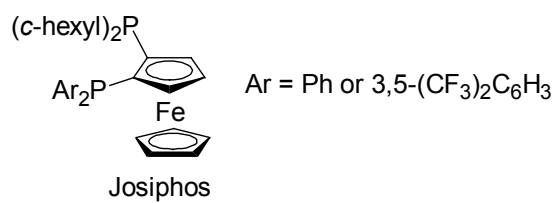

生物环加成的研究. 烯酮与邻苯醌、邻苯醌亚胺以及邻 苯醌双二酰亚胺等反应, 生成的产物在天然产物以及药 物合成中有很重要的用途. 如烯酮与邻苯醌亚胺反应生 成的 1,4-苯并噁嗪酮, 具有神经抗氧化保护活性和抗肿 瘤的作用, 作为活性结构单元存在许多临床药物以及天 然产物中. 而烯酮与邻苯醌双二酰亚胺反应得到的喹唑 酮，具有抗糖尿病、抗病毒、特别是抗艾滋等一系列生 物活性.

\section{1 金鸡纳碱催化体系}

2006 年 Lectka 小组 ${ }^{[34]}$ 报道了金鸡纳碱催化的烯酮 与邻苯醌的不对称 $[4+2]$ 环加成. 采用 $O$-苯甲酰奎宁丁 $(\mathrm{BQD}, \mathbf{2 b})$ 为亲核催化剂, 酰氯为烯酮前体, 在化学计 量 $\mathrm{EtN}(i-\mathrm{Pr})_{2}$ 的存在下, 一系列酰氯与四氯邻醌反应, 以 58\% 90\%的产率和 90\% 99\% ee 的高对映选择性得到 环加成产物. 所得产物经过两步简单转化, 可以用来合 成手性 $\alpha$-着基酸及其衍生物(Scheme 16).
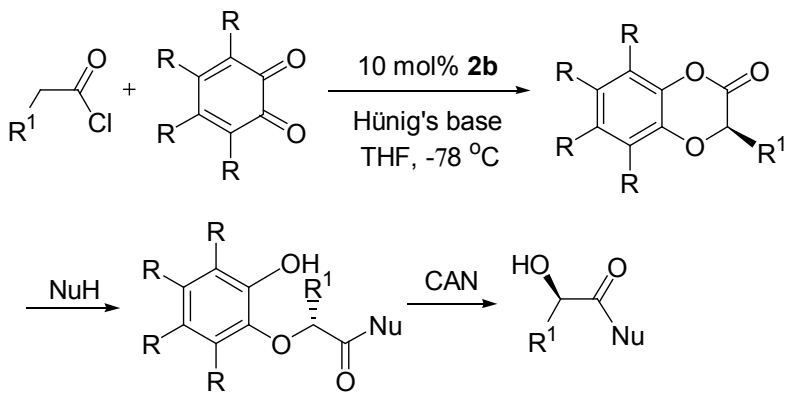

\section{Scheme 16}

为了提高反应的活性, Lectka 等 ${ }^{[35]}$ 将 Lewis 酸如 $\mathrm{Zn}(\mathrm{OTf})_{2}, \mathrm{Sc}(\mathrm{OTf})_{3}, \mathrm{In}(\mathrm{OTf})_{3}$ 等作为助催化剂引入到烯 酮和邻苯醌的[4+2]环加成反应中, 然而这些亲氧性的 Lewis 酸并不能活化邻苯醌. 相反, 在体系中引入亲氮 性的 $\mathrm{d}^{8}$ 组态的金属盐如 $\left(\mathrm{PPh}_{3}\right)_{2} \mathrm{PdCl}_{2},\left(\mathrm{PPh}_{3}\right)_{2} \mathrm{NiCl}_{2}$, $\left(\mathrm{PPh}_{3}\right)_{2} \mathrm{PtCl}_{2}$, 却能加快反应的速度, 提高加成产物和相 应 $\alpha$-羟基酸衍生物的产率，其中反式的 $\left(\mathrm{Ph}_{3} \mathrm{P}\right)_{2} \mathrm{PdCl}_{2}$ 表 现最为优秀. 进一步的红外、紫外和核磁研究以及 DFT 计算表明, 金属 Pd 并不是通过与邻苯醌配位起作用的, 而是通过与烯醇盐络合增强其稳定性，使得烯醇盐的浓 度增加, 从而加快反应速度的(Scheme 17).

采用 $O$-苯甲酰奎宁丁 $(\mathrm{BQD}, \mathbf{2 b})$ 作催化剂, 邻苯醌 亚胺也可以与酰氯在碱存在下发生 $[4+2]$ 环加成反应, 以 $61 \% \sim 77 \%$ 的产率得到几乎光学纯 $(>99 \% e e)$ 的手性 1,4-苯并噁嗪酮 ${ }^{[36]}$. 通过简单转化, 还可以得到对映体 纯的 1,4-苯并噁嗪和各种 $\alpha$-氨基酸的衍生物(Scheme 18). 因此邻苯醌亚胺与烯酮 $[4+2]$ 不对称环加成反应, 可以作为一个模板来制备光学纯的 $\alpha$-氨基酸及其衍生 物.

进一步的研究 ${ }^{[37]}$ 表明, Lewis 酸可以作为助催化剂 引入到反应中来活化邻苯醌亚胺, 提高环加成反应的产 率. Lectka 等发现, 在 $\mathrm{Sc}(\mathrm{OTf})_{3}$ 和 $O$-苯甲酰奎宁丁 (BQD，2b)共同催化下，二氯邻苯醌亚胺与烯酮的反应 速度加快, 加成产物现场醇解后得到 $\alpha$-氨基酸衍生物的 产率也明显提高，而反应的立体选择性仍然保持在 $99 \%$ $e e$ 以上(Eq. 20).

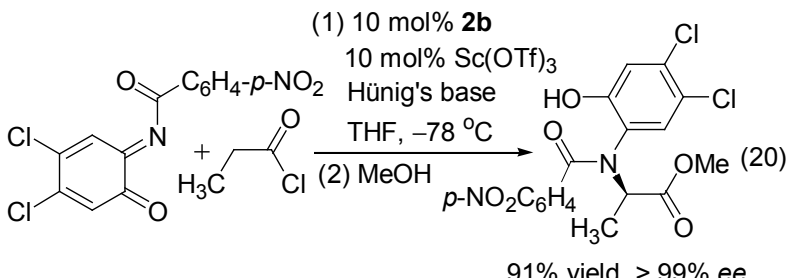

烯酮与邻苯醌双酰亚胺的环加成反应需要在 Lewis

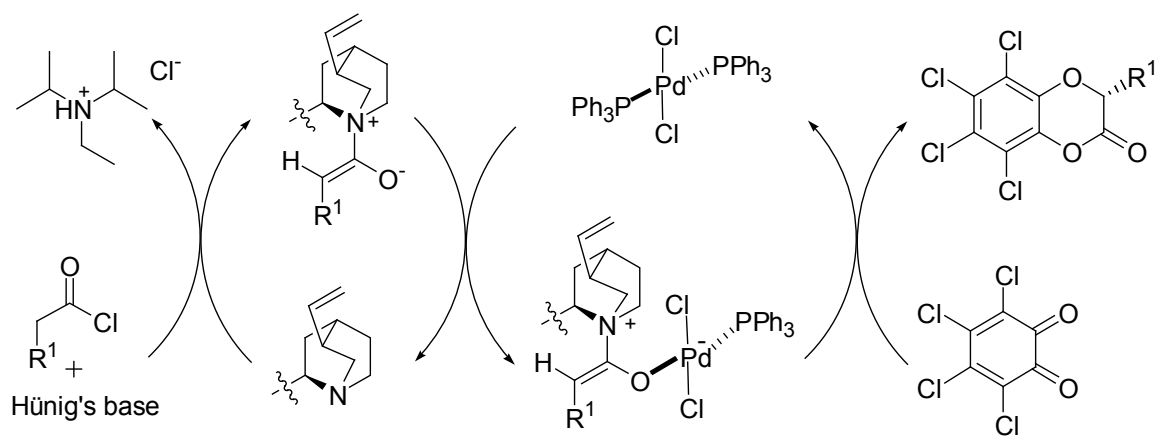

Scheme 17 

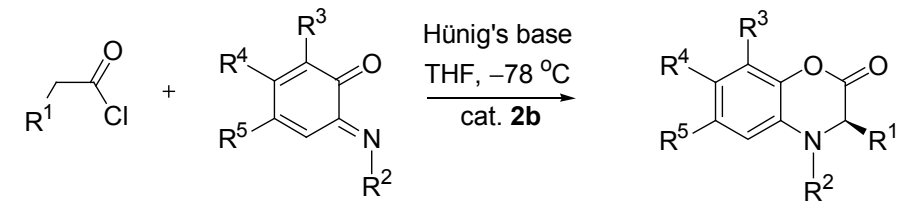

$61 \% \sim 77 \%$ yields, $>99 \%$ ee

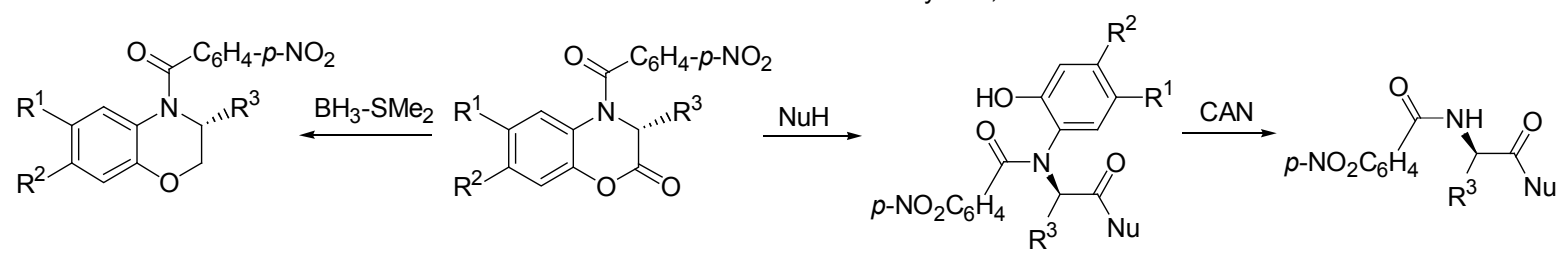

Scheme 18

酸和金鸡纳碱共同作用下才能完成 ${ }^{[38]}$. 采用 $\mathrm{Zn}(\mathrm{OTf})_{2}$ 作 为助催化剂, $O$-苯甲酰奎宁丁 (BQD, 2b) 为亲核催化剂, 酰氯为烯酮前体, 在 $\operatorname{EtN}(i-\operatorname{Pr})_{2}$ 存在下, 各种酰氯可以与 双酰亚胺反应生成喹唑酮 (Eq. 21). 反应产率较高 (69\% 93\%)且具有非常完美的对映选择性(>99\%ee). 采用 $O$-苯甲酰奎宁 $(\mathrm{BQ}, \mathbf{2 a})$ 与 Lewis 酸结合, 可以得到 光学纯的另一个构型的产物.

$$
\begin{aligned}
& \text { (21) } \\
& \begin{array}{ll}
\mathrm{R}^{1}=\mathrm{Cl}, \mathrm{CF}_{3}, \mathrm{COPh} & 69 \% \sim 93 \% \text { yields } \\
\mathrm{R}^{2}=\mathrm{Cl}, \mathrm{H} & >99 \% \mathrm{ee}
\end{array}
\end{aligned}
$$

Lectka 认为该反应经过了一个分步的反应机理, 即 烯酮在金鸡纳碱作用下活化生成两性离子烯醇盐, 而双 酰亚胺被 Lewis 活化, 使其 $\mathrm{N}$ 上的亲电增强, 容易受到 烯醇盐的亲核进攻，生成的中间体环化后就得到喹唑酮 (Scheme 19). 对于非对称的双酰亚胺, 两个 $N$ 的亲电性 不同, 烯醇盐更易进攻亲电性更强的那个 $\mathrm{N}$, 因此反应 具有区域专一性.

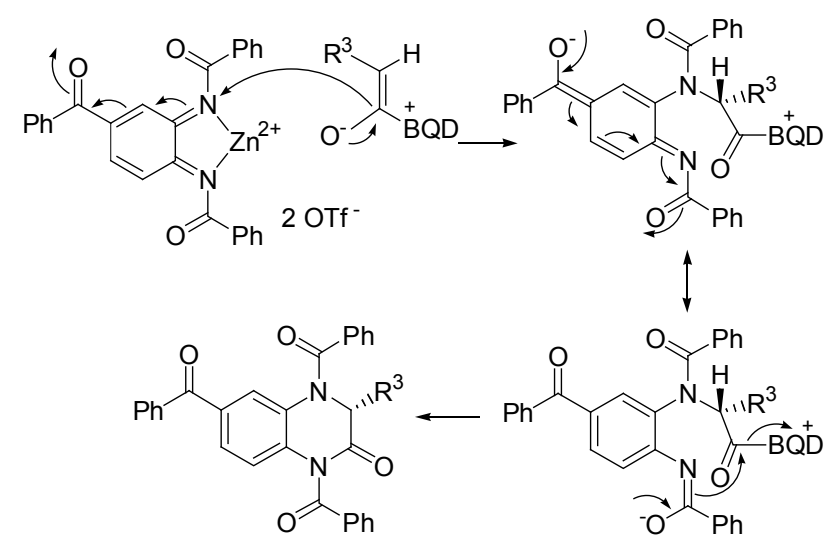

Scheme 19
2007 年, Nelson 等 ${ }^{[39}$ 报道了 $\mathrm{LiClO}_{4}$ 和 TMSQ(或 TMSQD)共同催化的烯酮和 $N$-硫酰亚胺的不对称 [4+2] 环加成(Scheme 20). 在反应中, 烯酮和亚胺是在碱性条 件下, 分别由酰氯和 $N$-杂缩醛现场生成的. Nelson 等认 为, $N$-硫酰亚胺和金鸡纳碱活化的烯醇盐, 通过与金属 Li 配位, 形成类椅式的环状过渡态, 因此该反应具有很 高的立体选择性( $>95: 5 d r,>95 \% e e)$.

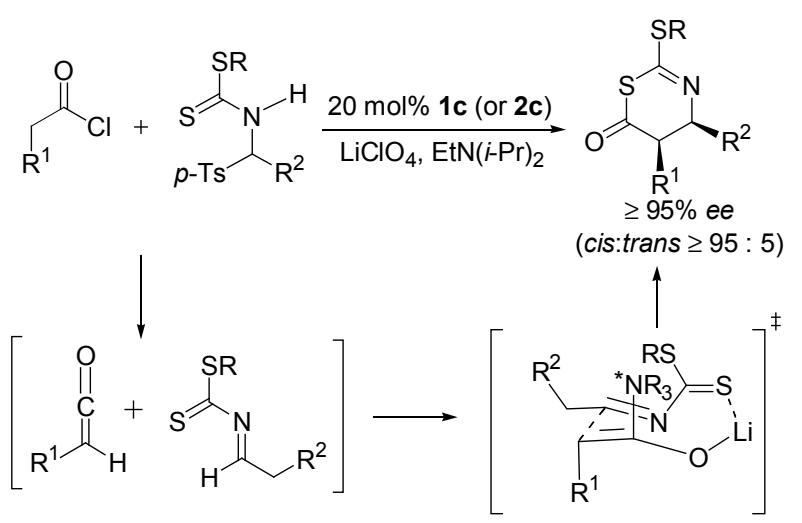

Scheme 20

\section{$3.2 \mathrm{~N}$-杂化卡宾 $(\mathrm{NHC})$ 催化体系}

最近叶松等 ${ }^{[40]}$ 也成功地将他们课题组发展的三唑 卡宾作为亲核催化剂应用到烯酮与葱醌的不对称 $[4+2]$ 环加成中, 以高达 $96 \%$ ee 的对映选择性得到环加成产 物(Eq. 22).

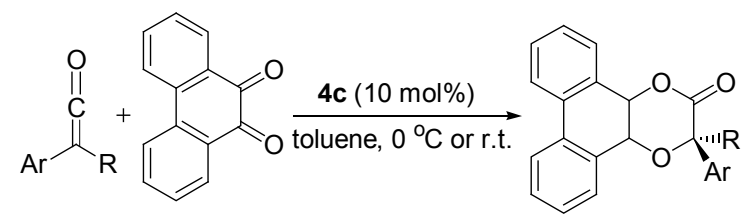

相对于烯酮与邻苯醌衍生物的 $[4+2]$ 环加成, 烯酮 与共轭烯酮的不对称环加成发展得比较晚. 反应生成的 $\delta$-内酯，具有抗菌、抗病毒、抗艾滋和抗癌的活性，是许 多天然产物和生物活性分子的核心结构. 
2008 年叶松等 ${ }^{[41]}$ 报道了第一例 $\mathrm{N}$-杂化卡宾催化的 烯酮和 $\alpha, \beta$-不饱和酮的不对称 [4+2]环加成. 使用他们 课题组发展的三唑卡宾作为催化剂, 各种烷芳基烯酮能 与芳基共轭烯酮发生加成反应, 以高达 39:1 $d r$ 的非对 映选择性和 $92 \% e e$ 的对映选择性得到含有 $\alpha$-季碳中心 和 $\beta$-叔碳中心的反式 $\delta$-内酯(Eq. 23).

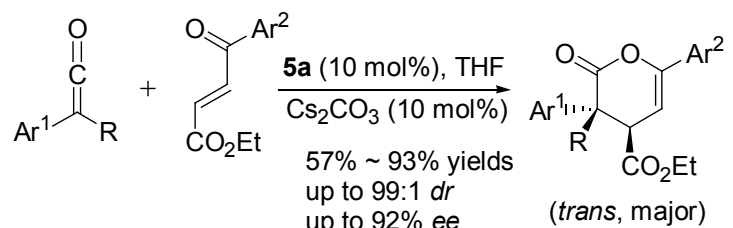

叶松等 ${ }^{[15]}$ 对烯酮和偶氮类化合物的环加成反应做 了进一步的研究, 发现当偶氮化合物由原来的偶氮二碳 酸酯变为苯甲酰偶氮化合物时，就可以实现其与烯酮的 不对称 $[4+2]$ 环加成反应. 通过改变 NHC 催化剂上的取 代基，可以获得相反构型的环加成产物(Eq. 24).<smiles>[R]N=NC([R])=O</smiles>

NHC 4a: 13 up to $96 \%$ ee NHC 4d: ent-13 up to $-97 \%$ ee

叶松等认为, 当使用 $4 \mathrm{a}$ 为催化剂时, $\mathrm{NHC}$ 与烯酮加 成形成的烯醇盐与苯甲酰偶氮化合物反应时, 采用平面 型的过渡态 $\mathbf{A}$, 即 $\mathrm{NHC}$ 上与 $\mathrm{N}$ 相连的苯环、三唑环和 烯醇都在同一平面; 而当使用 $4 \mathbf{d}$ 催化剂时, $\mathrm{NHC}$ 与烯 酮加成形成的烯醇盐采用垂直型的过渡态 $\mathbf{B}$, 即 $\mathrm{NHC}$ 上与 $\mathrm{N}$ 相连的 2,4,6-三甲基苯基和烯醇都与三唑环垂直 (Scheme 21).

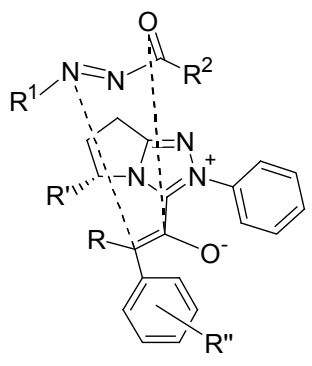

Coplanar TS A

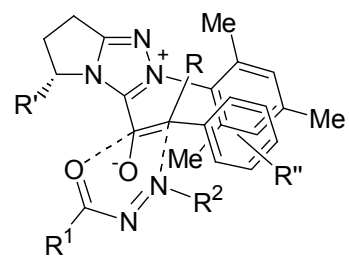

Perpendicular TS B

\section{Scheme 21}

随后叶松等又成功地将此类催化剂分别应用到烯 酮与邻亚甲基苯醌 ${ }^{[42]}$ 和与 3-亚甲基吲哚酮 ${ }^{[43]}$ 的环加成 反应中, 用来合成二氢香豆素和含有并环二氢吡喃酮结 构的吲哚酮(Eqs. 25 和 26).

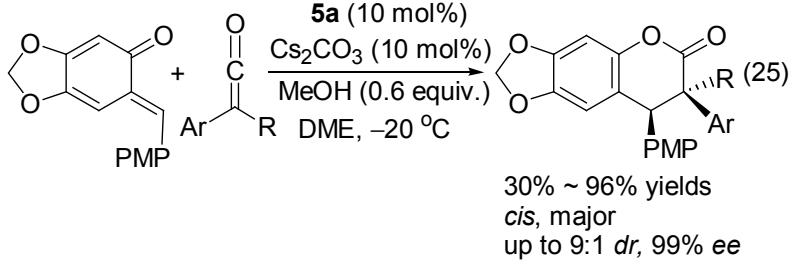

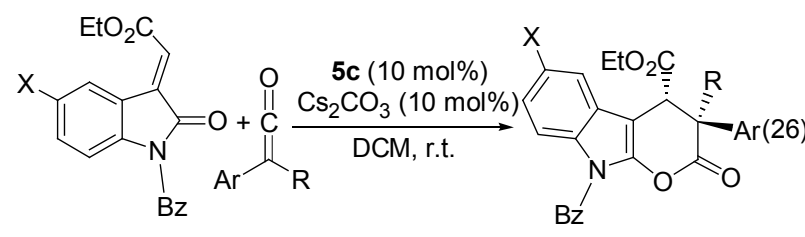

$88 \% \sim 99 \%$ yields up to $10: 1 d r, 90 \%$ ee

\section{4 总结}

综上所述，金鸡纳生物碱、含二茂铁结构的手性 PPY (4-pyrrolidinopyridine)以及 $\mathrm{N}$-杂化卡宾已作为三类 高效高选择性的亲核有机小分子催化剂，成功应用于烯 酮的不对称 $[2+2]$ 和 $[4+2]$ 环加成反应中. 而手性膦作 为一类新型的亲核催化剂，最近也在烯酮的二聚反应以 及烯酮与醛的 $[2+2]$ 环加成反应中初露头角. 烯酮的这 些环加成反应具有完美的原子经济性，符合可持续发展 的战略目标和绿色化学的要求, 反应生成的 $\beta$-内酰胺、 $\beta$-内酯等，是许多药物和天然产物的活性结构单元，可 以作为关键中间体应用于具有生物活性的天然产物和 药物的合成中，具有很好的应用前景. 发展高效、高选 择性、适用范围广泛的新型催化剂仍是这个研究领域面 临的挑战.

\section{References}

[1] Seebach, D. Chem. Int. Ed. 1979, 18, 239.

[2] Paull, D. H.; Weatherwax, A.; Lectka, T. Tetrahedron 2009, 65, 6771.

[3] Fang, Z.; Tang, R. R.; Luo, Z. W. Prog. Chem. 2008, 20, 1544 (in Chinese). (方钊，唐瑞仁，罗佐文，化学进展，2008，20, 1544.)

[4] Taggi, A. E.; Hafez, A. M.; Wack, H.; Young, B.; Drury, III, W. J.; Lectka, T. J. Am. Chem. Soc. 2000, 122, 7831.

[5] Taggi, A. E.; Hafez, A. M.; Wack, H.; Young, B.; Ferraris, D.; Lectka, T. J. Am. Chem. Soc. 2002, 124, 6626.

[6] France, S.; Wack, H.; Hafez, A. M.; Taggi, A. E.; Witsil, D. R.; Lectka, T. Org. Lett. 2002, 4, 1603.

[7] France, S.; Shah, M. H.; Weatherwax, A.; Wack, H.; Roth, J. P.; Lectka, T. J. Am. Chem. Soc. 2005, 127, 1206.

[8] Hodous, B. L.; Fu, G. C. J. Am. Chem. Soc. 2002, 124, 1578.

[9] Lee, E. C.; Hodous, B. L.; Bergin, E.; Shih, C.; Fu, G. C. J. Am. Chem. Soc. 2005, 127, 11586.

[10] Berlin, J. M.; Fu, G. C. Angew. Chem., Int. Ed. 2008, 47, 7048.

[11] Dochnahl, M.; Fu, G. C. Angew. Chem., Int. Ed. 2009, 48, 2391

[12] Zhang, Y.-R.; He, L.; Wu, X.; Shao, P.-L.; Ye, S. Org. Lett. 2008, $10,277$.

[13] Duguet, N.; Campbell, C. D.; Slawin, A. M. Z.; Smith, A. D. Org. 
Biomol. Chem. 2008, 6, 1108.

[14] Huang, X.-L.; Chen, X.-Y.; Ye, S. J. Org. Chem. 2009, 74, 7585.

[15] Huang, X.-L.; He, L.; Shao, P.-L.; Ye, S. Angew. Chem., Int. Ed. 2009, $48,192$.

[16] Sereda, O.; Blanrue, A.; Wilhelm, R. Chem. Commun. 2009, 1040.

[17] Wynberg, H.; Staring, E. G. J. J. Am. Chem. Soc. 1982, 104, 166.

[18] Wynberg, H.; Staring, E. G. J. J. Org. Chem. 1985, 50, 1977.

[19] Tennyson, R.; Romo, D. J. Org. Chem. 2000, 65, 7248.

[20] Zhu, C.; Shen, X. Q.; Nelson, S. G. J. Am. Chem. Soc. 2004, 126, 5352.

[21] Calter, M. A.; Tretyak, O. A.; Flaschenriem, C. Org. Lett. 2005, 7, 1809.

[22] Lin, Y. M.; Boucau, J.; Li, Z.; Casarotto, V.; Lin, J.; Nguyen, A. N.; Ehrmantraut, J. Org. Lett. 2007, 9, 567.

[23] Calter, M. A. J. Org. Chem. 1996, 61, 8006.

[24] Calter, M. A.; Guo, X.; Liao, W. S. Org. Lett. 2001, 3, 1499.

[25] Calter, M. A.; Orr, R. K.; Song, W. Org. Lett. 2003, 5: 4745.

[26] He, L.; Lv, H.; Zhang, Y.-R.; Ye, S. J. Org. Chem. 2008, 73, 8101.

[27] Wang, X.-N.; Shao, P.-L.; Lv, H.; Ye, S. Org. Lett. 2009, 11, 4029.

[28] Wang, X.-N.; Zhang, Y.-Y.; Ye, S. Adv. Synth. Catal. 2010, 352, 1892.

[29] Lv, H.; Zhang, Y.-R.; Huang, X.-L.; Ye, S. Adv. Synth. Catal. 2008, $350,2715$.

[30] Wilson, J. E.; Fu, G. C. Angew. Chem., Int. Ed. 2004, 43, 6358.

[31] Mondal, M.; Ibrahim, A. A.; Wheeler, K. A.; Kerrigan, N. J. Org.
Lett. 2010, 12, 1664.

[32] Ibrahim, A. A.; Harzmann, G. D.; Kerrigan, N. J. J. Org. Chem. 2009, 74, 1777.

[33] Ibrahim, A. A.; Wei, P. H.; Harzmann, G. D.; Kerrigan, N. J. J. Org. Chem. 2010, 75, 7901.

[34] Bekele, T.; Shah, M. H.; Wolfer, J.; Abraham, C. J.; Weatherwax, A.; Lectka, T. J. Am. Chem. Soc. 2006, 128, 1810.

[35] Abraham, C. J.; Paull, D. H.; Bekele, T.; Scerba, M. T.; Dudding, T.; Lectka, T. J. Am. Chem. Soc. 2008, 130, 17085.

[36] Wolfer, J.; Bekele, T.; Abraham, C. J.; Dogo-Isonagie, C.; Lectka, T. Angew. Chem., Int. Ed. 2006, 45, 7398.

[37] Paull, D. H.; Alden-Danforth, E.; Wolfer, J.; Dogo-Isonagie, C.; Abraham, C. J.; Lectka, T. J. Org. Chem. 2007, 72, 5380.

[38] Abraham, C. J.; Paull, D. H.; Scerba, M. T.; Grebinski, J. W.; Lectka, T. J. Am. Chem. Soc. 2006, 128, 13370.

[39] Xu, X.; Wang, K.; Nelson, S. G. J. Am. Chem. Soc. 2007, 129, 11690.

[40] Shao, P.-L.; Chen, X.-Y.; Sun, L.-H.; Ye, S. Tetrahedron Lett. 2010, 51, 2316.

[41] Zhang, Y.-R.; Lv, H.; Zhou, D.; Ye, S. Chem. Eur. J. 2008, 14, 8473.

[42] Lv, H.; You, L.; Ye, S. Adv. Synth. Catal. 2009, 351, 2822.

[43] Lv, H.; Chen, X.-Y.; Sun, L.-H.; Ye, S. J. Org. Chem. 2010, 75, 6973.

(Cheng, F.; Li, L.) 